De Clercq, Dirk, Haq, Inam Ul and Azeem, Muhammad Umer (2020) When does job dissatisfaction lead to deviant behaviour? The critical roles of abusive supervision and adaptive humour. Australian Journal of Management, 45(2), pp. 294-316. Copyright (C) 2019 (The Authors). DOI: https://doi.org/10.1177\% 2F0312896219877679 
When does job dissatisfaction lead to deviant behaviour? The critical roles of abusive supervision and adaptive humour

\author{
Dirk De Clercq \\ Inam Ul Haq \\ Muhammad Umer Azeem
}

Paper accepted for Australian Journal of Management 


\title{
When does job dissatisfaction lead to deviant behaviour? The critical roles of abusive supervision and adaptive humour
}

\begin{abstract}
With a basis in conservation of resources theory, this study investigates the relationship between employees' sense of job dissatisfaction and their engagement in deviant behaviour, as well as the moderating roles that their exposure to abusive leadership and possession of adaptive humour skills can play in this process. Based on two-way survey data collected from employees in Pakistan, the findings show that employees' unhappy feelings about their job situations enhance the likelihood that they undertake negative behaviours that can harm their organization, especially when they suffer from abusive leadership or lack adaptive humour skills. The buffering effect of their adaptive humour on the positive relationship between job dissatisfaction and deviant behaviour also is particularly salient in the presence of abusive leadership.
\end{abstract}

Keywords: deviant behaviour, job dissatisfaction, abusive supervision, adaptive humour, conservation of resources theory 


\section{Introduction}

The competitive standing and performance of organizations may be compromised to the extent that their employee bases engage in deviant behaviours, defined as behaviours that cause harm to the organization in general, its individual constituents, or both (Chung, 2017; Michel and Hargis, 2017; Wang et al., 2015; Wang et al., 2012; Zhang et al., 2018). Such behaviours might include deliberately damaging work property, spending time on personal matters while at work, intentionally working slower, refusing to work overtime, disobeying orders, failing to provide colleagues with useful information, or spreading negative rumours about coworkers (Skarlicki and Folger, 1997; Tepper et al., 2009). Not only are deviant behaviours harmful for the organization and its members-leading to diminished work productivity and tarnished morale among the targets of these behaviours, for example (Berry et al., 2007; Galperin and Burke, 2006; Moore et al., 2012) — but the performers of these behaviours can suffer too, in that their organizational rewards and career possibilities might be compromised if their efforts to undermine the organization's well-being come to light (Lievens et al., 2008, Martinko et al., 2002).

Why do employees engage in deviant behaviours then, despite the potential negative consequences (Hsieh and Wang, 2016; Michel and Hargis, 2017; Zhang et al., 2018)? Prior studies suggest several adverse job conditions that might spur deviant work behaviour, such as psychological contract breaches (Bordia et al., 2008), workplace harassment (Bowling and Beehr, 2006), perceptions of organizational unfairness (Yang et al., 2014), unethical leadership (Mo and Shi, 2017), or a Machiavellian corporate culture (Zheng et al., 2017). What these factors have in common is that they instil significant frustration in employees, spurring them to cause harm to their employer (Restubog et al., 2015). In addition to contextual factors, personal 
characteristics could determine the likelihood that people undertake deviant behaviour, such that this behaviour appears more likely among employees marked by high levels of moral disengagement (Christian and Ellis, 2014), a prevention focus (Lin and Johnson, 2018), or dark triad traits (Cohen, 2016).

One critical source of job adversity that also might inform employees' deviant behaviour is their sense of job dissatisfaction or lack of excitement or enthusiasm about their current job (Agho et al., 1992; Howard and Krannitz, 2017). In particular, employees may respond to such negative perceptions by engaging in deviant behaviour as a means to vent their frustration about their current job situation (Fox and Spector, 2006; Judge et al., 2006). In turn, we investigate when employees' negative job energy, in the form of job dissatisfaction, is more or less likely to translate into deviant behaviour, by focusing on two contingency factors: (1) the extent to which employees suffer exposure to abusive supervision, such that their leaders are verbally abusive and treat followers with hostility and disdain (Tepper, 2000), and (2) the extent to which they possess adaptive humour skills, defined as their reliance on wit or jokes in their interpersonal communication in response to challenging work situations (José et al., 2007).

\section{COR theory}

To ground the theoretical arguments about the effects of negative job energy on deviant behaviours, and the roles of abusive supervision and adaptive humour in this process, the current study relies on conservation of resources (COR) theory, which asserts that employees' work behaviours reflect their desires to avoid resource losses and obtain resource gains (Hobfoll, 1989, 2001). The COR logic suggests that employees' dissatisfaction with their job situation may enhance their deviant behaviour as a means to protect their current resource reservoirs (Hobfoll, 2001; Penney et al., 2011; Taylor et al., 2017). That is, the resource depletion that employees 
experience in the presence of an unhappy job situation—such as reduced professional and personal well-being (Bowling, 2010; Faragher et al., 2015)—generates significant frustration, which they may seek to release with work behaviours that cause harm to their organization or its members, to compensate for the resource depletion (Hobfoll and Shirom, 2000). Thus, when employees experience resource-depleting work situations, they may 'enter a defensive mode to preserve the self that is often aggressive and may become irrational' (Hobfoll et al., 2018: 10.4). Undertaking deviant behaviour can make dissatisfied employees feel better about themselves, because they can express their disappointment with their job (Krischer et al., 2010).

Previous applications of COR theory to predict deviant behaviour similarly indicate that, in the presence of resource-depleting job situations, employees 'engage in instrumental acts of deviance, behaviors that are counterproductive to work goals but yield resources to the individual, despite their negative impact on organizational goals' (Taylor et al., 2017: 156). Chiu and colleagues (2015) also point out that the COR logic is consistent with the frustrationaggression model, according to which unfavourable job conditions serve as catalysts for aggressive work behaviours that inflict harm on the organization (Berkowitz, 1989; Fox and Spector, 1999). We build on this extant research to conceptualize deviant behaviour as a behavioural response that employees adopt to protect their current resource reservoirs. That is, this behaviour functions as a coping mechanism that enables employees to vent their frustration about unhappy job-related feelings (Krischer et al., 2010; Taylor et al., 2017).

Moreover, COR theory predicts that this venting process, in response to job dissatisfaction, should be (1) reinforced by employees' exposure to resource-draining work circumstances that make their current job situation even worse, and accordingly increase their desire to express their job-related disappointments, but (2) buffered by their access to personal 
resources that can help them cope (Hobfoll, 2001; Hobfoll and Shirom, 2000). Similarly, we propose that employees' desire to release their frustration about an unhappy job situation, in the form of deviant behaviours, should be particularly strong in the presence of abusive supervision, because this leadership style accentuates the lack of support they receive from organizational authorities (Tepper et al., 2009). Moreover, in anticipation that abusive leaders might suffer if they engage in deviant behaviours, employees may experience resource gains, in the form of personal fulfilment, if they respond to job dissatisfaction in this way (Shoss et al., 2013). Employees' adaptive humour skills instead might protect them from the hardships associated with a lack of enthusiasm about their job (Romero and Cruthirds, 2006), such that their desire to respond with deviant behaviours should be mitigated. Relying on humour as a means to cope with negative work circumstances thus might mitigate the need to vent job-related frustration in the form of deviant behaviours.

\section{Contributions}

This study offers several contributions. First, the application of COR theory suggests how unhappy feelings about a job situation may spur employees to cause harm to their employer and its members, including a specification of how this process likely depends on two critical but understudied contingencies: (1) an external factor that relates to their treatment by organizational leaders (abusive supervision) and (2) an internal factor that informs their ability to cope with negative job energy (adaptive humour). Both factors influence the extent to which employees desire to channel negative job-related energy, due to an unhappy job situation, into harmful work behaviours, as a means to release this energy (Bowling, 2010; Fox and Spector, 2006; Hobfoll and Shirom, 2000; Judge et al., 2006). Exposure to abusive supervision increases this desire, as a means to punish dysfunctional leaders for the unsatisfactory job situation (Liu et al., 2010); 
reliance on adaptive humour skills diminishes the desire, because these personal skills enable employees to cope with or counter the negative job energy (Mesmer-Magnus et al., 2012). Together, these two contingencies thus provide a consistent, comprehensive perspective on how employees' behavioural responses to a negative job situation may depend on contextual and personal factors.

Second, in a more general sense, this study's focus on the moderating roles of abusive supervision and adaptive humour responds to calls to apply contingency approaches to the behavioural outcomes of negative job energy, to clarify when job adversity is more or less likely to escalate into harmful behavioural outcomes (Iacono et al., 2016; Michel and Hargis, 2017; Restubog et al., 2015; Zhang et al., 2018). This perspective complements prior research that investigates direct behavioural effects, such as studies that indicate a positive relationship between abusive supervision and workplace deviance (Liu et al., 2010; Wang et al., 2015) or a negative relationship between humour skills and work withdrawal (Mesmer-Magnus et al., 2012). By uncovering the more indirect role of these two factors, as manifest in their influence on employees' responses to a job situation that generates limited excitement or enthusiasm (Bowling, 2010; Restubog et al., 2015), this study provides organizations with expanded insight into how they can prevent negative job energy from escalating into harmful work behaviours: They should discourage dysfunctional leadership or nurture employees' pertinent humour skills.

Third, to establish a better understanding of the harmful behavioural consequences of employees' job dissatisfaction, this study reveals how the interplay of adequate humour skills and exposure to abusive supervision affects their propensity to engage in deviant behaviour. In particular, this study details the interdependent roles of both factors in terms of their influence on the harmful effect of negative job energy, an issue that has received little empirical attention in 
previous applications of COR theory to predict negative work outcomes (Garcia et al., 2018; Hobfoll and Shirom, 2000; Howard and Krannitz, 2017). Employees' reliance on adaptive humour, a critical personal resource, can mitigate their negative behavioural responses to jobrelated frustrations (José et al., 2007; Romero and Cruthirds, 2006), and this buffering role might be even stronger when employees are exposed to a resource-draining or abusive leadership style. Study context

With its empirical focus on the country of Pakistan, this study also addresses the need for research into the harmful behavioural outcomes of negative job situations in understudied, nonWestern settings (Alias et al., 2013; Biswas, 2016; Liu et al., 2010; Shamsudin et al., 2014). Pakistani culture is marked by high levels of uncertainty avoidance (Hofstede et al., 2010), so uncertainty-invoking job dissatisfaction might have a particularly strong effect on Pakistani employees' desire to vent their negative job energy through deviant behaviours (Bowling, 2010; Judge et al., 2006). Prior research also indicates that deviant behaviour is a common response to unfavourable job situations in Pakistani work settings, such as when employees believe that organizational decision making is unfair or marked by self-serving tendencies (Khan et al., 2013; Naseer et al., 2019; Nashir and Bashir, 2012).

Moreover, the two focal moderators in this study — abusive supervision and adaptive humour - are highly pertinent factors in this study context, because their hypothesized influences are not necessarily straightforward, in light of the cultural characteristics of this country. First, the high power distance that marks Pakistani culture implies that employees could regularly encounter organizational leaders who exhibit disrespectful or hostile tendencies (De Clercq et al., 2018; Hofstede et al., 2010), which then may generate greater frustration in combination with an already unsatisfactory job situation. Yet the tendency to defer to authority associated with this 
cultural factor also could cause employees to be somewhat compliant with abusive leadership styles (Khan et al., 2017). Second, the broader cultural environment in which employees operate tends to determine the extent to which they rely on humour when they confront stressful work conditions (Robert and Yan, 2007; Wang et al., 2018), but this effect might not be straightforward in Pakistan. In this high power distance, collectivistic country, employees could rely on adaptive humour to make jokes about themselves and put their unhappy job situation into perspective (Hofstede et al., 2010). Or they might fear that their use of humour will violate cultural norms for blending in and invoke reprimands (Kalliny et al., 2006; Robert and Yan 2007). Taken together, Pakistan thus represents an interesting, compelling context in which to investigate the concurrent effects of employees' sense of job dissatisfaction, exposure to abusive supervision, and possession of adaptive humour skills on their deviant behaviours.

\section{Conceptual model}

Figure 1 depicts the proposed conceptual framework and its constitutive hypotheses. It first links employees' job dissatisfaction with their enhanced deviant behaviour, then predicts that this relationship depends on two contingencies: abusive supervision and adaptive humour. In line with COR theory (Hobfoll, 1989, 2001), employees' negative job energy should enhance their deviant behaviour (1) to a greater extent when they suffer from resource-draining abusive supervision but (2) to a lesser extent when they can draw from their personal resource of adaptive humour. In turn, the buffering effect of this personal resource should be particularly strong when employees experience abusive supervision.

[Insert Figure 1 about here]

\section{Research hypotheses}

\section{Job dissatisfaction and deviant behaviour}


According to COR theory, employees' work behaviours are largely driven by their motivation to protect their current resource reservoirs and prevent further resource losses when they have negative feelings about their job situation (Hobfoll, 1989, 2001). As mentioned, this theory conceptualizes deviant work behaviours as behavioural responses through which employees seek to release their disappointment about unfavourable job circumstances (Hobfoll et al., 2018; Penney et al., 2011). We similarly posit that the frustration that comes with resourcedraining job dissatisfaction may spur deviant behaviours, as a coping strategy that allows employees to vent the frustration they feel toward a job that offers them little excitement (Hobfoll, 2001; Krischer et al., 2010; Taylor et al., 2017).

In particular, to the extent that employees have negative feelings about their job situation, they feel motivated to protect themselves by exhibiting work behaviours that can undo the associated frustration (Penney et al., 2011). For example, employees who feel bored with their job tend to be frustrated with the lack of opportunities for further career development (Rayton and Yalabik, 2014; Skowronski, 2012; Sun and Pan, 2008), so any actions that enable them to express their disappointment can help them cope with this precarious career situation (Bowling, 2010; Jones, 2009). That is, a negative behavioural response to a lack of happiness feels warranted and limits further resource losses, by making employees feel less bad about their career (Hobfoll and Shirom, 2000). Similarly, employees who find little enjoyment in the execution of their job tasks may attribute these negative feelings to a lack of organizational support for their personal well-being (Bowling, 2010; Shamsudin et al., 2014). In turn, they can avoid additional resource losses by releasing the negative energy that comes with this attribution, through dysfunctional work activities that threaten the well-being of their organization or its members (Fox and Spector, 2006; Taylor et al., 2017). 
Finally, unsatisfied employees may undertake deviant behaviours to conserve their energy, which also aligns with the logic underpinning COR theory. That is, job-related frustration may steer employees' energy toward negative activities, such as delaying current work practices (Devonish, 2013; Hsieh and Wang, 2016). For example, a sense of boredom may prompt dissatisfied employees to redirect their focus, away from making energy-consuming positive work contributions and toward intentionally undermining their organization's internal functioning by being passive (Crede et al., 2007; Iacono et al., 2016). Accordingly, the likelihood that they undertake deviant behaviours should be higher to the extent that employees are less happy with their job situation.

Hypothesis 1: Employees' job dissatisfaction relates positively to their engagement in deviant behaviour.

\section{Invigorating role of abusive supervision}

Consistent with COR theory (Hobfoll and Shirom, 2000), employees' negative job energy, due to their sense of job dissatisfaction, also may escalate into deviant behaviours more forcefully to the extent that they are exposed a resource-draining leadership style, such as abusive supervision (Whitman et al., 2014; Wu and Lee, 2016). Organizational leaders with abusive tendencies are verbally aggressive and behave in demeaning ways toward followers (Tepper, 2000). Verbal abuse represents a critical source of resource depletion for employees, because they feel unappreciated for their work efforts and worry about their ability to meet their job obligations (Frieder et al., 2015; Haar et al., 2016; Xu et al., 2015). In this scenario, employees may be even more inclined to respond to any negative feelings that they already have about their job situation with deviant behaviours, because dysfunctional leadership provides an additional argument that their organization does not care for their well-being, which then further spurs their motivation to vent their frustration with their job situation (Liu et al., 2010; Shoss et 
al., 2013). In line with COR theory (Hobfoll and Shirom, 2000), employees' desire to avoid further resource losses and vent their frustration about an unhappy job situation, by undertaking deviant behaviours, thus should be greater to the extent that abusive supervision, another source of resource depletion (Whitman et al., 2014), marks their day-to-day work experiences.

The enhanced propensity to channel negative job energy into harmful activities in the presence of abusive supervision also may be explained by anticipated resource gains, in the form of personal fulfilment, when employees can take revenge for a job situation marked by both a sense of boredom and exposure to aggressive, disrespectful leaders (Shoss et al., 2013; Wang et al., 2015). In particular, when organizational leaders are hostile and demeaning, employees might be especially motivated to channel their frustrations about a less-than-exciting job situation into deviant activities that could undermine the well-being of those leaders and that reflect the employees' sense of deservedness (Hobfoll, 2001; Liu et al., 2010; Wu and Lee, 2016). If instead organizational leaders show respect and empathy, employees have less reason to blame them for the unhappy job situation (Kernan et al., 2016), so they should gain less personal fulfilment from using their negative job energy to undertake deviant behaviours (Bowling, 2010).

Hypothesis 2: Employees' exposure to abusive supervision moderates the positive relationship between their job dissatisfaction and engagement in deviant behaviour, such that the positive relationship is stronger at higher levels of abusive supervision.

\section{Mitigating role of adaptive humour}

The risk that employees' unhappy feelings about their job situation escalate into enhanced deviant behaviour may be mitigated by those employees' adaptive humour skills. Employees who feel unhappy about their job situation but can draw on their adaptive humour skills are better positioned to deal with the associated job-related frustrations, by putting these negative experiences into perspective — such as with the realization that 'there are worse things 
in life' than not feeling happy about a job—and also being able to undo this adverse situation if they use their wit to influence organizational decision makers (Lehmann-Willenbrock and Allen, 2014; Romero and Cruthirds, 2006). That is, a sense of humour is a personal resource from which employees might draw to counter the negative consequences of an unhappy job situation by convincing influential others to find creative solutions for the difficult situation (Amabile, 1996; Lang and Lee, 2010). Conversely, employees who cannot rely on such humour skills but experience frustration about their current job situation might become overwhelmed by their continuous ruminations and feelings of anger (Lyttle, 2007; Romero and Cruthirds, 2006). In this scenario, they should feel a stronger desire to vent their job-related frustrations by undertaking deviant behaviours (Bowling, 2010). Employees with limited ability to use humour to deal with job adversity then might be particularly enticed to express their disappointment about their negative job situation by causing harm to the organization or its members (Hobfoll and Shirom, 2000).

In a related sense, employees who use humour to cope with challenging job situations tend to be more effective in communicating about these situations with their immediate colleagues, and thus, colleagues might be more receptive to their complaints (Pouthier, 2017; Wijewardena et al., 2016). Such enhanced peer communication in turn can provide employees with greater insight into the reasons the employer fails to meet all their job expectations for example (Mesmer-Magnus et al., 2012), which should diminish their desire to vent their frustrations about their negative job situation through deviant behaviour (Fox and Spector, 2006; Judge et al., 2006). Thus, the collegial support generated from communication with other members-who also might be more likely to vent their own job-related frustrations with employees who display a good sense of humour (Jalalkamali et al., 2018; Lehmann-Willenbrock 
and Allen, 2014; Smith and Khojasteh, 2014)—should reduce employees' propensity to undertake deviant behaviours in response to an unhappy job situation, because they gain an enhanced ability to put their negative job situation in perspective (Mesmer-Magnus et al., 2012).

Hypothesis 3: Employees' adaptive humour moderates the positive relationship between their job dissatisfaction and engagement in deviant behaviour, such that the positive relationship is weaker among employees with higher levels of adaptive humour.

Finally, this buffering role of adaptive humour may be especially potent when employees also have to endure organizational leaders with abusive tendencies. We thus predict a three-way interaction among employees' sense of job dissatisfaction, possession of adaptive humour skills, and exposure to abusive supervision. When the quality of their organizational functioning is undermined by resource-draining abusive leaders, employees' personal resource of adaptive humour should be particularly important for preventing their negative job energy from escalating into enhanced deviant behaviours (Abel, 1998; Hobfoll, 2001; Sliter et al., 2014). That is, their ability to engage other organizational members through humour and find effective solutions to their job adversity should be particularly useful in this scenario. In turn, employees can reserve discretionary energy for positive instead of negative activities, because they can effectively counter their frustration with insights about how to undo their adverse job situation (Romero and Cruthirds, 2006). Thus, when employees suffer from severe hostility from leaders, the extent to which they can draw from their personal resource of adaptive humour should be particularly useful for mitigating the risk that their resource depletion, caused by their unsatisfactory job situation, escalates into enhanced deviance as a means to vent their frustrations (Hobfoll, 2001). Conversely, when employees are not victims of verbal leader abuse, the relative value of applying their adaptive humour to avoid transforming negative job energy into deviant behaviour decreases (Mesmer-Magnus et al., 2012). 
Hypothesis 4: Employees' exposure to abusive supervision moderates the buffering effect of their adaptive humour on the positive relationship between their job dissatisfaction and deviant behaviour, such that this buffering effect is stronger among employees exposed to higher levels of abusive supervision.

\section{Research method}

\section{Sample and data collection}

The tests of the hypotheses relied on survey data collected from employees of five Pakistani organizations that operate in different industries: manufacturing, banking, education, media, and telecommunication. Including these five organizations ensured the representation of a broad selection of sectors, which increased both data heterogeneity and confidence in the generalizability of the findings. Further, these organizations were not part of foreign groups, so their internal work cultures are more likely to reflect Pakistani cultural values. ${ }^{1}$ One of the authors relied on existing professional contacts to identify targeted organizations and obtain the organizations' agreement to participate. This author then conducted personal visits to the organizations' sites to distribute surveys. After they had completed the surveys, the randomly chosen participants put them into sealed envelopes and returned them to the author. They were informed that the results would benefit their organization's internal functioning, but they did not receive any monetary or other reward to take part.

Several measures protected the rights of the participants. In particular, the invitation letters that accompanied the surveys explained the general objective of the study, underscored complete confidentiality, and indicated that participation was completely voluntary. Further, we emphasized that no individual-level data would ever be released to the public and that only summary findings would be available to people outside the research team. The cover letter also

\footnotetext{
${ }^{1}$ We did not explicitly assess the work cultures in the different organizations, but informal interactions with organizational contact persons, prior to the data collection, broadly indicated that they all were marked by relatively authoritarian cultures, focused on task efficiency and compliance. These features speak to the relevance of two of our focal constructs, namely, job dissatisfaction and abusive supervision.
} 
explained that the surveys included a personal code, so that the data could be matched between the two survey rounds, but that this personal code would not compromise confidentiality in any way. Moreover, the letter listed the contact information for a member of the research team, so participants could ask questions or raise concerns as needed, and the respondents also were informed about their right to withdraw from the study at any point. Finally, we explicitly noted that there were no correct or incorrect answers and asked participants to complete the surveys as honestly as possible, which helps reduce acquiescence and social desirability biases (Spector, 2006).

The data collection process included two surveys, separated by a three-week time lag. This time lag was long enough to avoid recall bias but not too long that significant organizational events could have occurred during the study. The first survey asked employees about their satisfaction with their current job situation, their perceptions about their supervisor, and their humour skills; the second survey gauged their engagement in deviant behaviour. Because English is the official language of instruction in schools and business communication in most professional organizations in Pakistan, the survey questions were administered in English.

A total of 360 surveys were distributed to potential participants in the five organizations, identified through random selections from employee lists provided by the human resource departments of the participating organizations. Thus, we used convenience sampling to select the five organizations, which facilitated our access to the research sites, but the data collection within organizations was random, to ensure that the sampled employees were representative of their organizations. Table 1 summarizes response information for the five organizations, as well as the demographic characteristics of their respondents. To account for organization- (or industry)-specific effects, we controlled for the organization in the statistical analyses. Of the 
360 distributed surveys, the first round produced a total of 280 responses, and the second survey provided a total of 221 completed response sets, for an overall response rate of $61 \% .^{2}$

[Insert Table 1 about here]

\section{Measures}

The measures of the study constructs use items from previously validated scales and fivepoint Likert scales ranging from 1 ('strongly disagree') to 5 ('strongly agree').

Employees' engagement in deviant behaviour features a 17-item scale of retaliatory behaviour, developed by Skarlicki and Folger (1997). The scale includes harmful behaviours that target the organization (e.g., 'I waste company materials,' 'I intentionally work slower,' 'I refuse to work weekends or overtime when asked') and individual members (e.g., 'I give coworkers the silent treatment,' 'I fail to give coworkers required information,' 'I disobey supervisor instructions'). The measure offered adequate reliability (Cronbach's alpha $=.89$ ).

The job dissatisfaction measure relies on a reverse-coded, six-item scale of job satisfaction (Abbas et al., 2014; Agho et al., 1992), consistent with prior research that investigates employees' negative job energy or frustration (e.g., Jiang et al., 2009). One item in the original scale ('I am often bored with my job') already reflected job dissatisfaction and did not require reverse coding. Two other example items are 'Most days I am enthusiastic about my work' and 'I find enjoyment in my work' (Cronbach's alpha $=.69) .{ }^{3}$

A five-item scale, developed by Tepper (2000), measures employees' beliefs about the abusive supervision tendencies of their leaders. For example, respondents indicated whether 'My

\footnotetext{
${ }^{2}$ A comparison of respondents with non-respondents between the first and second rounds in terms of key demographic characteristics (gender, age, education, and organizational tenure) indicated no significant differences. ${ }^{3}$ One item ('I am satisfied with my job for the time being') exhibited low correlation with the other items and did not appear in the final analysis.
} 
boss ridicules me,' 'My boss tells me that my thoughts or feelings are stupid,' or 'My boss tells me I am incompetent' (Cronbach's alpha $=.91)$.

To assess employees' reliance on adequate adaptive humour skills, we draw on the Multidimensional Sense of Humour Scale (Thorson and Powell, 1993), and particularly the fouritem subscale of adaptive humour, as validated by José and colleagues (2007). This subscale measures employees' ability to cope with job adversity through their humour. Two example items are 'The use of wit helps me master difficult situations' and 'The use of humour helps to put me at ease' (Cronbach's alpha $=.80)$.

The statistical models controlled for four demographic variables: gender $(1=$ female $)$, age $(1=$ less than 20 years, $2=20-29$ years, $3=30-39$ years, $4=40-49$ years, $5=50-59$ years, $6=60$ years or older $)$, education $(1=$ master's degree $)$, and organizational tenure $(1=$ less than 5 years; $2=5-9$ years; $3=10-14$ years, $4=15-19$ years, and $5=20$ or more years). Previous research indicates that men may have a higher propensity than women to undertake negative work activities (Bowling and Burns, 2015) and that the emotional maturity associated with age may make it less likely that older employees seek to cause harm to their organization (Carstensen, 1992). Employees' education and organizational tenure also may inform their confidence that they can protect themselves against negative consequences of their deviant behaviours (Martinenko et al., 2002). As mentioned, we also controlled for the organization, using four dummy variables; the organization from the banking industry was the base category.

\section{Results}

Table 2 contains the correlation coefficients and descriptive statistics, and Table 3 reports the hierarchical regression results. The variance inflation factors (VIF) were all lower than the conservative threshold of 5.0 (Studenmund 1992), so multicollinearity was not a concern in the 
regression analysis. ${ }^{4}$ Model 1 included the control variables, Model 2 added job dissatisfaction and the two moderators, and Models 3-4 added the two interaction terms: job dissatisfaction $\times$ abusive supervision and job dissatisfaction $\times$ adaptive humour. Including multiple interaction terms separately is appropriate, because their simultaneous inclusion in a single model can mask true moderating effects (Aiken and West, 1991; Covin et al., 2006; De Clercq and Belausteguigoitia, 2017). Model 5 added the three-way interaction term, job dissatisfaction $\times$ adaptive humour $\times$ abusive supervision, together with the three constitutive two-way interactions. Before calculating the two- and three-way interactions, the product terms were mean-centered (Aiken and West, 1991).

[Insert Tables 2 and 3 about here]

In support of the baseline premise that employees' unhappy feelings about their job situation enhance their desire to release their frustation, Model 2 reveals a positive relationship between job dissatisfaction and deviant behaviour $(\beta=.197, p<.01)$. Although beyond the scope of this study's theoretical focus, Model 2 also indicates a direct (weak) positive relationship between abusive supervision and deviant behaviour $(\beta=.071, p<.10)$ and a negative relationship between adaptive humour and deviant behaviour $(\beta=-.186, p<.001)$.

Model 3 affirms the hypothesized moderating effect of abusive supervision $(\beta=.259, p<$ $.01)$; the likelihood that job dissatisfaction translates into enhanced deviant behaviour is greater to the extent that employees perceive abusive tendencies in their leaders. Moreover, evidence for the buffering effect of adaptive humour emerges from its negative interaction with job dissatisfaction in Model $4(\beta=-.384, p<.001)$. Negative job energy is less likely to escalate into deviant behaviour when employees can rely on their adaptive humour skills. According to

\footnotetext{
${ }^{4}$ The highest VIF for the regression coefficients that did not pertain to the organization dummy variables - which should have higher VIF values because of the correlated dummy categories - equalled 2.025.
} 
corresponding slope analyses (Aiken and West, 1991), as Figure 2 reveals, the relationship between job dissatisfaction and deviant behaviour is significant and positive at high levels of abusive supervision $(\beta=.456, p<.001)$ but not at low levels $(\beta=.062, n s)$. In Figure 3 , the relationship between job dissatisfaction and deviant behaviour is positive and significant when adaptive humour is low $(\beta=.556, p<.001)$ but non-significant when it is high $(\beta=-.212, n s)$.

[Insert Figures 2 and 3 about here]

The results also indicate a significant three-way interaction among job dissatisfaction, adaptive humour, and abusive supervision (Model 5, $\beta=-.289, p<.05$ ). To clarify the nature of this interaction, Figure 4 plots the moderating effects of adaptive humour on the relationship between job dissatisfaction and deviant behaviour at high versus low levels of abusive supervision. At high levels (Panel A), the interaction plot pattern is similar to that in Figure 3: The positive relationship between job dissatisfaction and deviant behaviour disappears when employees can rely on their adaptive humour skills. However, with low abusive supervision (Panel B), the two lines are nearly parallel, indicating the absence of an interaction effect between job dissatisfaction and adaptive humour. As Dawson and Richter (2006) recommend, we also assessed the significance of the slope differences. It was significant in Panel A $(\mathrm{t}=-$ $3.920, p<.001)$ but not in Panel B $(\mathrm{t}=-.503, n s)$, in further support of $\mathrm{H} 4$.

[Insert Figure 4 about here]

Even though the theoretical focus of this study is on the concurrent interplay of job dissatisfaction, abusive supervision, and adaptive humour skills for predicting deviant behaviour, we also undertook a post hoc analysis to account for possible interdependencies among these constructs, such as the possibility that employees' job dissatisfaction might be influenced by the type of leadership to which they are exposed or the humour skills they possess. Accordingly, we 
ran three path models, corresponding with the three regression Models 3-5 in Table 3, that included covariances among job dissatisfaction, abusive supervision, and adaptive humour. The results were consistent with the findings generated from the regression analysis. The direct effect of job dissatisfaction, as well as the moderating effects of abusive supervision and adaptive humour, remained robust after accounting for possible causal interdependencies among these constructs (De Clercq et al., 2009).

\section{Discussion}

This study extends extant scholarship by examining the effect of employees' sense of job dissatisfaction on their deviant behaviour, as well as the roles of negative leadership conditions (abusive supervision) and positive employee skills (adaptive humour) in this process. Previous research reveals direct effects of these factors on employee work behaviours (e.g., Liu et al., 2010; Mesmer-Magnus et al., 2012) but does not address how they might inform the likelihood that employees leverage their negative job energy, due to unhappy feelings about their current job situation, into an enhanced propensity to cause harm to their organization or its members. Consistent with COR theory, the resource depletion that arises with job dissatisfaction may spur deviant behaviour, as a means to avoid further resource losses and enable employees to express their disappointment with a negative job situation (Hobfoll, 2001; Penney et al., 2011; Taylor et al., 2017). This process appears particularly salient to the extent that employees are exposed to organizational leaders with abusive tendencies but less prominent when employees can draw from their adaptive humour skills. The buffering effects of humour skills on the positive relationship between job dissatisfaction and deviant behaviour also might be especially strong in the presence of abusive supervision. The empirical findings confirm these theoretical predictions. 
When employees lack enthusiasm about their job, the associated frustrations may develop into a desire to harm to their employer or its members, as a way to release their negative energy and feel better again about their organizational functioning (Bowling, 2010). That is, 'deviance represents a means of adjusting to a frustrating job' and 'dissatisfied employees may engage in deviant behavior as a cathartic means of restoring control over the job' (Judge et al., 2006: 128). Employees who feel unhappy about their job situation likely perceive limited appreciation for their daily work effort and contributions (Judge et al., 2006), and consistent with the logic of COR theory (Hobfoll and Shirom, 2000), they respond with work behaviours that reduce the chances of additional resource depletion and help them express their disappointment (Krisher et al., 2010; Penney et al., 2011). In addition, the experience of job-related frustration may drain employees' positive energy levels, such that they allocate less time to productive work efforts and instead seek to conserve their work energy — by slowing down their work pace or taking excessively long time breaks, for example — even if doing so compromises the well-being of their employer (Foote and Tang, 2008; Frooman et al., 2012; Hobfoll, 2001).

This positive effect of job dissatisfaction on deviant behaviour is stronger when employees have to deal with abusive organizational leaders (Figure 2). The invigorating effect of this resource-draining form of leadership is consistent with the COR argument that the desire to vent frustration - to avoid further resource losses in the presence of a resource-draining, unhappy job situation-increases in the presence of work conditions in which such energy releases have particularly great value (Hobfoll and Shirom, 2000; Liu et al., 2010). That is, the release of negative job energy, due to an unhappy job situation, achieved by causing harm to the organization feels particularly meaningful when organizational leaders are aggressive and do nothing to improve their followers' job situations (Whitman et al., 2014). Such deviant responses 
also may appear particularly acceptable in this scenario, if employees believe that people in leadership positions will be the primary victims of their harmful behaviours (Shoss et al., 2013). The allocation of negative job energy toward deviant work behaviours thus may generate resource gains in the form of positive feelings of fulfilment (Hobfoll and Shirom, 2000), because employees consider their reactions to an unfavourable job situation particularly justified in this scenario (Shoss et al. 2013; Wang et al., 2015).

Employees' adaptive humour skills instead function as buffers against the likelihood that employees vent their frustrations about an unsatisfactory job situation in the form of deviant behaviour (Figure 3). Employees equipped with adequate humour skills are better positioned to protect themselves against the frustration that comes with this unfavourable job situation, by giving it less weight (José et al., 2007; Sliter et al. 2014) and influencing key organizational members to resolve the unfavourable job situation (Romero and Cruthirds, 2006). To the extent that employees have a good sense of humour, they are better placed to engage other organizational decision makers to find adequate solutions and perhaps regain enthusiasm about their job. The enhanced peer communication that results from the use of humour in interpersonal exchanges (Pouthier, 2017) also may reveal why their employer might not be able to meet all their needs, so their desire to vent their frustration through deviant behaviour tends to be subdued. Their peers also likely share their own experiences and ways to deal with a negative job situation with funny coworkers, so employees with adaptive humour skills obtain and can use the associated insights to resolve their frustrations (Lehmann-Willenbrock and Allen, 2014).

As Figure 4 reveals, this buffering role of adaptive humour is particularly salient when employees suffer from resource-draining abusive supervision. When causing harm to the organization in response to an unhappy job situation appears particularly meaningful and 
attractive, because such responses can negatively affect the well-being of abusive leaders, the personal resource of adaptive humour becomes especially useful for preventing negative job energy from escalating into enhanced deviant behaviours (Abel, 1998; Mesmer-Magnus et al., 2012). Overall, these findings offer a more complete view of when a sense of job dissatisfaction enhances the likelihood that employees vent their frustation through deviant behaviours. In particular, the current study extends previous research by specifying the concurrent, interdependent influences of job dissatisfaction, exposure to abusive supervision, and possession of adequate humour skills on the likelihood of deviant behaviour. Adaptive humour is instrumental in preventing job dissatisfaction from escalating into enhanced deviant behaviours, but particularly so when employees feel threatened by abusive leaders.

\section{Limitations and further research}

This study has some limitations that indicate areas for further research. First, the time lag of three weeks between the measures of the independent and moderator variables on the one hand and the dependent variable on the other mitigates concerns about reversed causality. However, continued research could use longitudinal designs with longer time frames and explicitly examine the time-based processes that link the experience of job dissatisfaction with deviant behaviour, as well as boundary conditions on this process. Nor does the current study directly measure the mechanisms theorized to link employees' negative job feelings with deviant behaviour. Our central premise is that deviant behaviour functions as a coping mechanism that helps employees release their frustration about an unhappy job situation (Krischer et al., 2010; Penney et al., 2011; Taylor et al., 2017), but various fine-grained mechanisms might inform this release. For example, employees may associate a lack of job-related enthusiasm with a lack of organizational support for their career development or personal well-being (Bowling, 2010; 
Faragher et al., 2015), in which case they may develop a desire to express their disappointment, and feel better about themselves in the process, by causing harm to their employer or its members (Skarlicki and Folger, 1997). Continued research could measure these mechanisms directly. It also would be useful to assess whether the positive effect of job dissatisfaction on deviant behaviour might differ depending on the source of the negative job situation—from inside the workplace or from the outside, such as unmet financial family needs or conflicting work and family demands (Witt and Carlson, 2006).

Second, by focusing on the moderating roles of two specific contingency factors, one contextual and one personal, this study ignores other pertinent factors that might determine the extent to which negative job energy escalates into heightened deviant behaviours. For example, unhappy employees may engage in deviant behaviour to a greater extent if their desire to vent their job-related frustration gets invigorated by adverse work conditions, such as an organization that breaches its psychological contract with employees (Cassar and Briner, 2011), engages in dysfunctional or political decision making (Abbas et al., 2014), or applies unfair rewards systems (Colquitt et al., 2001). Other personal characteristics also could prevent employees from leveraging their negative job energy into deviant behaviours, such as resilience (Linnenluecke, 2017), tenacity (Baum and Locke, 2004), or creative self-efficacy (Tierney and Farmer, 2002). Such research could complement self-reported measures of these contingency factors with observer ratings, including for the measurement of this study's focal moderators. For example, it would be interesting to assess other organizational members' opinions about employees' humor skills, as well as to explicate different forms of humor that employees might use to deal with dissatisfactory work conditions, including but not limited to adaptive humor. 
Third, our sample included five organizations that operate in different industries, and we accordingly controlled for this factor. Notably, we found support for the hypothesized relationships, even after including these control variables, so the study variables appear robust, irrespective of organization-specific factors. Nonetheless, the possibility of omitted variable bias remains, so further research might include additional variables that speak specifically to the work culture, such as the extent to which the organizational climate endorses authoritarian decision making (Khan et al., 2017) or embraces the use of humour in intra-firm communication (Kalliny et al., 2006). Furthermore, an organization's internal work culture might be directly informed by its industry; it would accordingly be useful to investigate pertinent industry influences, such as the level of market rivalry or turbulence in its industry sector (Porter, 1996). For example, employees whose organizations operate in industries with excessive competitive pressures might be more understanding when their employer cannot satisfy each of their individual wishes (Lahiri et al., 2008), so the likelihood that they respond to their personal disappointments with deviant behaviour might diminish.

Fourth, as we detailed when describing the study context, Pakistan and its cultural values provide a compelling context, because the hypothesized moderating effect relationships, though highly relevant, are not straightforward. In particular, the high power distance might make some employees more accepting of or even compliant with abusive leadership styles (Khan et al., 2017), and collectivism norms might cause employees to avoid standing out through the use of humour (Wang et al., 2018). In this sense, this study provided a conservative test of the hypotheses. Nonetheless, our focus on one country might constrain the generalizability of the results. Cross-country comparisons could clarify whether and how the negative energy that arises with a sense of job dissatisfaction informs the likelihood that employees engage in deviant work 
behaviours, as well as the roles that distinct contingency factors play in this process in various cultures.

\section{Practical implications}

The findings point to the challenges that organizations encounter when employees seek to release their frustrations with a job situation by deliberately causing harm to their employer or coworkers. When employees feel unhappy about their job situation—which may be manifest in a sense of boredom or limited enthusiasm about coming to work (Agho et al., 1992) — the employer needs to address the underlying sources. However, some employees may be reluctant to admit outright that they are dissatisfied with their current job situation, so organizational decision makers must be proactive in detecting which employees might be experiencing negative job energy and then taking measures to counter this experience. For example, organizations should establish a culture that promotes open communication about job-related frustrations (Wang and Noe, 2010). An appointed ombudsman also might address employee concerns on an independent, confidential basis (Harrison et al., 2013).

Yet the presence of some employee unhappiness may be unavoidable, particularly if organizations cannot keep all of their previously made promises because they face excessive external pressures or changing competitive circumstances, for example (Lahiri et al., 2008; Morrison and Robinson, 1997). In such cases, organizations must be even more dedicated to eliminating abusive tendencies among managers and leaders. For example, they could gather feedback from employees about the presence of such abusive tendencies, while also working to eliminate their possible causes, such as excessive work pressures on leaders or ineffective promotion policies. Organizations also might benefit from leadership training programs that 
underscore the need to exhibit respect and empathy toward followers, instead of treating them with disdain or hostility (Gentry et al., 2014).

In turn, employees who can effectively use humour in challenging job situations are better positioned to deal with their frustrations. This personal resource offers a critical means by which organizations can protect against employees' tendency to vent their job-related frustrations in the form of deviance. To nurture and leverage employees' adaptive humour skills, organizations could train employees in the usefulness of developing healthy relativism, putting disappointing job situations into perspective, and maintaining a minimum level of positive energy to channel into productive work activities, even if employees are not completely happy with all aspects of their job (Romero and Cruthirds, 2006). Any measure that enhances employees' abilities to apply humour during interactions with other organizational members should be especially valuable in work situations in which some frustrations simply cannot be eliminated completely. Employees who possess stronger humour skills are better positioned to adopt adequate coping strategies that constrain the hardships evoked by a sense of boredom and limited excitement about their job.

\section{Conclusion}

This study has examined how and when employees' sense of job dissatisfaction increases their propensity to engage in deviant behaviour. Negative feelings about their job situations spur deviance as a means to release their disappointment, particularly among employees who suffer from organizational leaders who engage in verbal abuse toward them. Such employees, who already suffer from an unsatisfactory job situation, may interpret their exposure to abusive supervision as an additional indication that their organization does not care for their professional or personal well-being, which further stimulates their desire to release their job-related 
frustrations by undertaking deviant behaviours. However, their adaptive humour skills have significant buffering roles-in terms of both preventing job dissatisfaction from escalating into enhanced deviant behaviours and containing the harmful effects of abusive supervision in this process. In turn, this study might serve as a platform for further investigations of how organizations can avoid a situation in which negative job energy steers employees toward deviant behaviours, such as by promoting supportive instead of dysfunctional leadership styles and honing employees' personal skills to cope more effectively with negative job situations. 


\section{References}

Abbas, M., Raja, U., Darr, W., and Bouckenooghe, D. (2014). Combined effects of perceived politics and psychological capital on job satisfaction, turnover intentions, and performance. Journal of Management, 40, 1813-1830.

Abel, M.H. (1998). Interaction of humor and gender in moderating relationship between stress and outcomes. Journal of Psychology, 132, 267-276.

Agho, A. O., Price, J. L., and Mueller, C. W. (1992). Discriminant validity of measures of job satisfaction, positive affectivity, and negative affectivity. Journal of Occupational Psychology, 65, 185-196.

Aiken, L.S., and West, S.G. (1991). Multiple regression: Testing and interpreting interactions. Newbury Park, CA: Sage.

Alias, M. , Rasdi, R.M., Ismail, M., and Samah, B.A. (2013). Influences of individual-related factors and job satisfaction on workplace deviant behaviour among support personnel in Malaysian public service organizations. Human Resource Development International, 16, 538-557.

Amabile, T.M. (1996). Creativity in context. Boulder, CO: Westview.

Baum, J.R., and Locke, E.A. (2004). The relationship of entrepreneurial traits, skill, and motivation to subsequent venture growth. Journal of Applied Psychology, 89, 587-598.

Berkowitz, L. (1989). Frustration-aggression hypothesis: examination and reformulation. Psychological Bulletin, 106, 59-73.

Berry, C.M., Ones, D. S., and Sackett, P. R. (2007). Interpersonal deviance, organizational deviance, and their common correlates: A review and meta-analysis. Journal of Applied Psychology, 92, 410-424.

Biswas, S. (2016). Behavioural and attitudinal outcomes of psychological contract violation. Journal of Management Development, 35, 261-279.

Bordia, P., Restubog, S.L.D., and Tang, R.L. (2008). When employees strike back: Investigating mediating mechanisms between psychological contract breach and workplace deviance. Journal of Applied Psychology, 93, 1104-1117.

Bowling, N.A. (2010). Effects of job satisfaction and conscientiousness on extra-role behaviours. Journal of Business and Psychology, 25, 119-130.

Bowling, N.A., and Beehr, T.A. (2006). Workplace harassment from the victim's perspective: A theoretical model and meta-analysis. Journal of Applied Psychology, 91, 998-1012.

Bowling, N.A., and Burns, G. N. (2015). Sex as a moderator of the relationships between predictor variables and counterproductive work behaviour. Journal of Business and Psychology, 30. 193-205.

Carstensen, L.L. (1992). Social and emotional patterns in adulthood: Support for socio-emotional selectivity theory. Psychology and Aging, 7, 331-338.

Cassar, V., and Briner, R.B. (2011). The relationship between psychological contract breach and organizational commitment: Exchange imbalance as a moderator of the mediating role of violation. Journal of Vocational Behaviour, 78, 283- 289.

Chiu, S.-F., Yeh, S.-P., and Huang, T.C. (2015). Role stressors and employee deviance: the moderating effect of social support. Personnel Review, 44, 308-324.

Christian, J.S., and Ellis, A.P. (2014). The crucial role of turnover intentions in transforming moral disengagement into deviant behaviour at work. Journal of Business Ethics, 119, 193208. 
Chung, Y.W. (2017). The role of person-organization fit and perceived organizational support in the relationship between workplace ostracism and behavioural outcomes. Australian Journal of Management, 42, 328-349.

Cohen, A. (2016). Are they among us? A conceptual framework of the relationship between the dark triad personality and counterproductive work behaviours (CWBs). Human Resource Management Review, 26, 69-85.

Colquitt, J.A., Conlon, D.E., Wesson, M.J., Porter, C.O.L.H., and Ng, K.Y (2001). Justice at the millennium: a meta-analytic review of 25 years of organizational justice research. Journal of Applied Psychology, 86, 425-445.

Covin, J.G., Green, K.M., and Slevin, D.P. (2006). Strategic process effects on the entrepreneurial orientation-sales growth rate relationship. Entrepreneurship Theory and Practice, 30, 57-81.

Crede, M., Chernyshenko, O.S., Stark, S., Dalal, R.S., and Bashshur, M. (2007). Job satisfaction as mediator: An assessment of job satisfaction's position within the nomological network. Journal of Occupational and Organizational Psychology, 80, 515-538.

Dawson, J.F., and Richter, A.W. (2006). Probing three-way interactions: The development and application of a slope difference test. Journal of Applied Psychology, 91, 917-926.

De Clercq, D., and Belausteguigoitia, I. (2017). Mitigating the negative effect of perceived organizational politics on organizational citizenship behaviour: Moderating roles of contextual and personal resources. Journal of Management and Organization, 23, 689-708.

De Clercq, D., Haq, I.U., Raja, U., Azeem, M.U., and Mahmud, N. (2018) When is an Islamic work ethic more likely to spur helping behaviour? The roles of despotic leadership and gender. Personnel Review, 47, 630-650.

De Clercq, D., Thongpapanl, N., and Dimov, D. (2009). When good conflict gets better and bad conflict becomes worse: the role of social capital in the conflict-innovation relationship. Journal of the Academy of Marketing Science, 37, 283-297.

Devonish, D. (2013). Workplace bullying, employee performance and behaviours: The mediating role of psychological well-being. Employee Relations, 35, 630-647.

Faragher, E. B., Cass, M., and Cooper, C. L. (2005). The relationship between job satisfaction and health: A meta-analysis. Occupational Environmental Medicine, 62, 105-112.

Foote, D.A., and Tang, T.L.-P. (2008). Job satisfaction and organizational citizenship behaviour (OCB): Does team commitment make a difference in self-directed teams? Management Decision, 46, 933-947.

Fox, S., and Spector, P. E. (1999). A model of work frustration-aggression. Journal of Organizational Behavior, 20, 915-931.

Fox, S., and Spector, P.E. (2006). The many roles of control in a stressor-emotion theory of counter productive work behaviour. In P.L. Perrewe and D.C. Ganster (Eds.), Research in occupational stress and well being (pp. 171-201). Greenwich, CT: JAI.

Frieder, R.E., Hochwarter, W.A., and DeOrtentiis, P.S. (2015). Attenuating the negative effects of abusive supervision: The role of proactive voice behaviour and resource management ability. Leadership Quarterly, 26, 821-837.

Frooman, J., Mendelson, M.B., and Murphy, J.K. (2012). Transformational and passive avoidant leadership as determinants of absenteeism. Leadership and Organization Development Journal, 33, 447-463. 
Galperin, B.L., and Burke, R.J. (2006). Uncovering the relationship between workaholism and workplace destructive and constructive deviance: An exploratory study. International Journal of Human Resource Management, 17, 331-347.

Garcia, P.R.J.M., Bordia, P., Restubog, S.L.D, and Caines, V. (2018). Sleeping with a broken promise: The moderating role of generativity concerns in the relationship between psychological contract breach and insomnia among older workers. Journal of Organizational Behaviour, 39, 326-338.

Gentry, W.A., Eckert, R.H., Munusamy, V.P., Stawiski, S.A., and Martin, J.L. (2014). The needs of participants in leadership development programs: A qualitative and quantitative crosscountry investigation. Journal of Leadership and Organizational Studies, 21, 83-101.

Haar, J.M., de Fluiter, A., and Brougham, D. (2016). Abusive supervision and turnover intentions: The mediating role of perceived organisational support. Journal of Management and Organization, 22, 139-153.

Harrison, T.R., Hopeck, P., Desrayaud, M., and Imboden, K. (2013). The relationship between conflict, anticipatory procedural justice, and design with intensions to use ombudsman processes. International Journal of Conflict Management, 24, 56-72.

Hobfoll, S.E. (1989). Conservation of resources. A new attempt at conceptualizing stress. American Psychologist, 44, 513-524.

Hobfoll, S.E. (2001). The influence of culture, community, and the nested-self in the stress process: Advancing conservation of resource theory. Applied Psychology: An International Review, 50, 337-369.

Hobfoll, S.E., Halbesleben, J., Neveu, J.-P., and Westman, M. (2018). Conservation of resources in the organizational context. The reality of resources and their consequences. Annual Review of Organizational Psychology and Organizational Behaviour, 5, 103-128.

Hobfoll, S.E., and Shirom, A. (2000). Conservation of resources theory: Applications to stress and management in the workplace. In R.T. Golembiewski (Ed.), Handbook of organization behaviour (2d ed., pp. 57-81). New York: Dekker.

Hofstede, G.H., Hofstede, G.J., and Minkov, M. (2010). Cultures and organizations: Software of the mind. Intercultural cooperation and its importance for survival (3d ed.). New York: McGraw-Hill.

Howard, M., and Krannitz, M. (2017). A reanalysis of occupation and suicide: Negative perceptions of the workplace linked to suicide attempts. Journal of Psychology, 151, 767788.

Hsieh, H.-H., and Wang, Y.-D. (2016). Linking perceived ethical climate to organizational deviance: The cognitive, affective, and attitudinal mechanisms. Journal of Business Research, 69, 3600-3608.

Iacono, J.L., Weaven, S.K., and Griffin, D. (2016). Examination into the effects of job satisfaction on salesperson deviance: The moderating role of customer orientation. Journal of Business Economics and Management, 17, 173-186.

Jalalkamali, M., Iranmanesh, M., Nikbin, D., and Hyun, S.S. (2018). An empirical analysis of the effects of humor on communication satisfaction and job performance in international joint ventures in Iran. Journal of Management and Organization, 24, 295-311.

Jiang, B., Baker, R.C., and Frazier, G.V. (2009). An analysis of job dissatisfaction and turnover to reduce global supply chain risk: Evidence from China. Journal of Operations Management, 27, 169-184. 
Jones, D.A. (2009). Getting even with one's supervisor and one's organization: relationships among types of injustice, desires for revenge, and counterproductive work behaviours. Journal of Organizational Behaviour, 30, 525-542.

José, H., Parreira, P., Thorson, J.A., and Allwardt, D. (2007). A factor-analytic study of the multidimensional sense of humor scale with a Portuguese sample. North American Journal of Psychology, 9, 595-610.

Judge T.A., Scott B.A., and Ilies, R. (2006). Hostility, job attitudes, and workplace deviance: Test of a multilevel model. Journal of Applied Psychology, 91, 126-138.

Kalliny, M., Cruthirds, K.W., and Minor, M.S. (2006). Differences between American, Egyptian and Lebanese humor styles: Implications for international management. International Journal of Cross Cultural Management, 6, 121-134.

Kernan, M.C., Racicot, B.M., and Fisher, A.M. (2016). Effects of abusive supervision, psychological climate, and felt violation on work outcomes: A moderated mediated model. Journal of Leadership and Organizational Studies, 23, 309-321.

Khan, A.K., Quratulain, S., and Crawshaw, J.R. (2013). The mediating role of discrete emotions in the relationship between injustice and counterproductive work behaviours: A study in Pakistan. Journal of Business and Psychology, 28, 49-61.

Khan, A.K., Quratulain, S. and Crawshaw, J. (2017). Double jeopardy: Subordinates' worldviews and poor performance as predictors of abusive supervision. Journal of Business and Psychology, 32, 165-178.

Krischer, M.M., Penney, L.M., and Hunter, E.M. (2010). Can counterproductive work behaviours be productive? CWB as emotion-focused coping. Journal of Occupational Health Psychology, 15, 154-166.

Lahiri, S., Pérez-Nordtvedt, L., and Renn, R.W. (2008). Will the new competitive landscape cause your firm's decline? It depends on your mindset. Business Horizons, 51, 311-320.

Lang, J.C., and Lee, C.H. (2010). Workplace humor and organizational creativity. International Journal of Human Resource Management, 21, 46-60.

Lehmann-Willenbrock, N., and Allen, J.A. (2014). How fun are your meetings? Investigating the relationship between humor patterns in team interactions and team performance. Journal of Applied Psychology, 99, 1278 - 1287.

Lievens, F., De Corte, W., and Schollaert, E. (2008). A closer look at the frame-of-reference effect in personality scale scores and validity. Journal of Applied Psychology, 93, 268-279.

Lin, S.-H., and Johnson, R.E. (2018). Opposing affective and cognitive effects of prevention focus on counterproductive work behaviour. Journal of Business and Psychology, 33, 283296.

Linnenluecke, M.K. (2017). Resilience in business and management research: A review of influential publications and a research agenda. International Journal of Management Reviews, 19, 4-30.

Liu, J., Kwan, H.K., Wu, L.-Z., and Wu, W. (2010). Abusive supervision and subordinate supervisor-directed deviance: The moderating role of traditional values and the mediating role of revenge cognitions. Journal of Occupational and Organizational Psychology, 83, $835-856$.

Lyttle, J. (2007). The judicious use and management of humor in the workplace. Business Horizons, 50, 239-245. 
Martinko, M.J., Gundlach, M.J., and Douglas, S.C. (2002). Toward an integrative theory of counterproductive workplace behaviour: A causal reasoning perspective. International Journal of Selection and Assessment, 10, 36-50.

Mesmer-Magnus, J., Glew, D.J., and Chockalingam, V. (2012). A meta-analysis of positive humor in the workplace. Journal of Managerial Psychology, 27, 155-190.

Michel, J.S., and Hargis, M.B. (2017). What motivates deviant behaviour in the workplace? An examination of the mechanisms by which procedural injustice affects deviance. Motivation and Emotion, 41, 51-68.

Mo, S., and Shi, J. (2017). Linking ethical leadership to employee burnout, workplace deviance and performance: Testing the mediating roles of trust in leader and surface acting. Journal of Business Ethics, 144, 293-303.

Moore, C., Detert, J.R., Treviño, L.K., Baker, V.L., and Mayer, D.M. (2012). Why employees do bad things: Moral disengagement and unethical organizational behaviour. Personnel Psychology, 65, 1-48.

Morrison, E.W., and Robinson, S.L. (1997). When employees feel betrayed: A model of how psychological contract violation develops. Academy of Management Review, 22, 226-256.

Naseer, S., Bouckenooghe, D., Syed, F., Khan, A.K., and Qazi, S. (2019). The malevolent side of organizational identification: unraveling the impact of psychological entitlement and manipulative personality on unethical work behaviours. Journal of Business and Psychology, doi:10.1007/s10869-019-09623-0

Nasir, M., and Bashir, A. (2012). Examining workplace deviance in public sector organizations of Pakistan. International Journal of Social Economics, 39, 240-253.

Penney, L.M., Hunter, E.M., and Perry, S.J. (2011). Personality and counterproductive work behaviour: Using conservation of resources theory to narrow the profile of deviant employees. Journal of Occupational and Organizational Psychology, 84, 58-77.

Porter, M.E. (1996). What is strategy? Harvard Business Review, 74, 61-81.

Pouthier, V. (2017). Griping and joking as identification rituals and tools for engagement in cross-boundary team meetings. Organization Studies, 38, 753-774.

Rayton, B.A., and Yalabik, Z.Y. (2014). Work engagement, psychological contract breach and job satisfaction. International Journal of Human Resource Management, 25, 2382-2400.

Restubog, S.L.D., Zagenczyk, T.J., Bordia, P., Bordia, S., and Chapman, G.J. (2015). If you wrong us, shall we not revenge? Moderating roles of self-control and perceived aggressive work culture in predicting responses to psychological contract breach. Journal of Management, 41, 1132-1154.

Robert, C., and Yan, W. (2007). The case for developing new research on humor and culture in organizations: toward a higher grade of manure. Research in Personnel and Human Resources Management, 26, 205-267.

Romero, E.J., and Cruthirds, K.W. (2006). The use of humor in the workplace. Academy of Management Perspectives, 20, 58-69.

Shamsudin, F.M., Subramaniam, C., and Sri Ramalu, S. (2014). The influence of HR practices and job satisfaction on interpersonal deviance in the workplace. Journal of Management and Organization, 20, 691-709.

Shoss, M.K.,, Eisenberger, R., Restubog, S.L.D., and Zagenczyk, T.J. (2013). Blaming the organization for abusive supervision: The roles of perceived organizational support and supervisor's organizational embodiment. Journal of Applied Psychology, 98, 158-168. 
Skarlicki, D.P., and Folger, R. (1997). Retaliation in the workplace: The roles of distributive, procedural, and interactional justice. Journal of Applied Psychology, 82, 434-443.

Skowronski, M. (2012). When the bored behave badly (or exceptionally). Personnel Review, 41, $143-159$.

Sliter, M.., Kale, A., Yuan, Z. (2014). Is humor the best medicine? The buffering effect of coping humor on traumatic stressors in firefighters. Journal of Organizational Behaviour, 35, 257272.

Smith, J.W., and Khojasteh, M. (2014). Use of humor in the workplace. International Journal of Management and Information Systems, 18.

Spector, P.E. (2006). Method variance in organizational research: Truth or urban legend? Organizational Research Methods, 9, 221-232.

Studenmund, A.H. (1992). Using econometrics: A practical guide. New York: Harper Collins. pp. 395-419. ISSN (print) 0266-2426.

Sun, L.-Y., and Pan, W. (2008). HR practices perceptions, emotional exhaustion, and work outcomes: A conservation-of-resources theory in the Chinese context. Human Resource Development Quarterly, 19, 55-74.

Taylor, E.C., Bernerth, J.B., and Maurer, J.D. (2017). Running on empty: The effects of aggregate travel stress on team performance. Journal of Business and Psychology, 32, 513531.

Tepper, B. J. (2000). Consequences of abusive supervision. Academy of Management Journal, 43, 178-190.

Tepper B.J., Carr J.C., Breaux D.M., Geider S., Hu C., and Hua W. (2009). Abusive supervision, intentions to quit, and employees' workplace deviance: A power/dependence analysis. Organizational Behaviour and Human Decision Processes, 109, 156-167.

Thorson, J., and Powell, F (1993). Development and validation of a multidimensional sense of humor scale. Journal of Clinical Psychology, 49, 13-23.

Tierney, P., and Farmer, S.M. (2002). Creative self-efficacy: Potential antecedents and relationship to creative performance. Academy of Management Journal, 45, 1137-1148.

Wang, G., Harms, P.D., and Mackey, J.D. (2015). Does it take two to tangle? Subordinates' perceptions of and reactions to abusive supervision. Journal of Business Ethics, 131, 487503.

Wang, R., Kwan Shing Chan, D., Goh, Y.W., Penfold, M., Harper, T., and Weltewitz, T. (2018). Humor and workplace stress: A longitudinal comparison between Australian and Chinese employees. Asia Pacific Journal of Human Resources, 56, 175-195.

Wang, S., and Noe, R.A. (2010). Knowledge sharing: A review and directions for future research. Human Resource Management Review, 20, 115-131

Wang, W., Mao, J., Wu, W., and Liu, J. (2012). Abusive supervision and workplace deviance: the mediating role of interactional justice and the moderating role of power. Asia Pacific Journal of Human Resources, 50, 43-60.

Whitman, M.V., Halbesleben, J.R.B, and Holmes, O., IV (2014). Abusive supervision and feedback avoidance: The mediating role of emotional exhaustion. Journal of Organizational Behaviour, 35, 38-53.

Wijewardena, N., Samaratunge, R., Härtel, C., and Kirk-Brown, A. (2016). Why did the emu cross the road? Exploring employees' perception and expectations of humor in the Australian workplace. Australian Journal of Management, 41, 563-584. 
Witt, L.A., and Carlson, D.S. (2006). The work-family interface and job performance: Moderating effects of conscientiousness and perceived organizational support. Journal of Occupational Health Psychology, 11, 343-357.

Wu, W.-L., and Lee, Y.-C. (2016). Do employees share knowledge when encountering abusive supervision? Journal of Managerial Psychology, 31, 154-168.

$\mathrm{Xu}$, A.J., Loi, R., and Lam, L.W. (2015). The bad boss takes it all: How abusive supervision and leader-member exchange interact to influence employee silence. Leadership Quarterly, 26, 763-774.

Yang, L.-Q., Bauer, J., Johnson, R.E., Groer, M.W., and Salomon, K. (2014). Physiological mechanisms that underlie the effects of interactional unfairness on deviant behaviour: The role of cortisol activity. Journal of Applied Psychology, 99, 310-321.

Zhang, C., Mayer, D.M., and Hwang, E. (2018). More is less: Learning but not relaxing buffers deviance under job stressors. Journal of Applied Psychology, 103, 123-136.

Zheng, W., Wu, Y.-C.J., Chen, X.C., and Lin, S.-J. (2017). Why do employees have counterproductive work behaviour? The role of founder's Machiavellianism and the corporate culture in China. Management Decision, 55, 563-578. 
Figure 1: Conceptual model

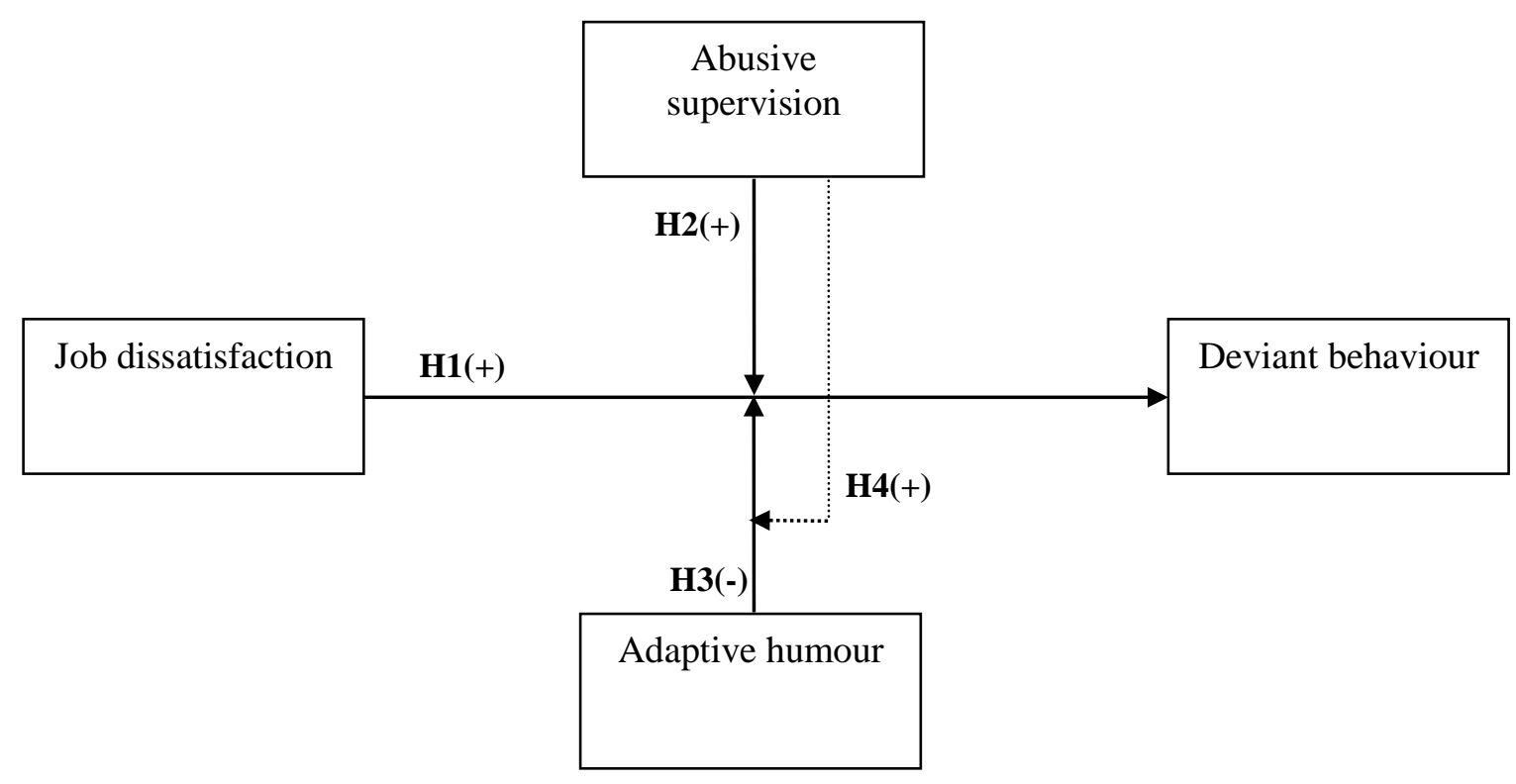


Figure 2: Moderating effect of abusive supervision on the relationship between job dissatisfaction and deviant behaviour

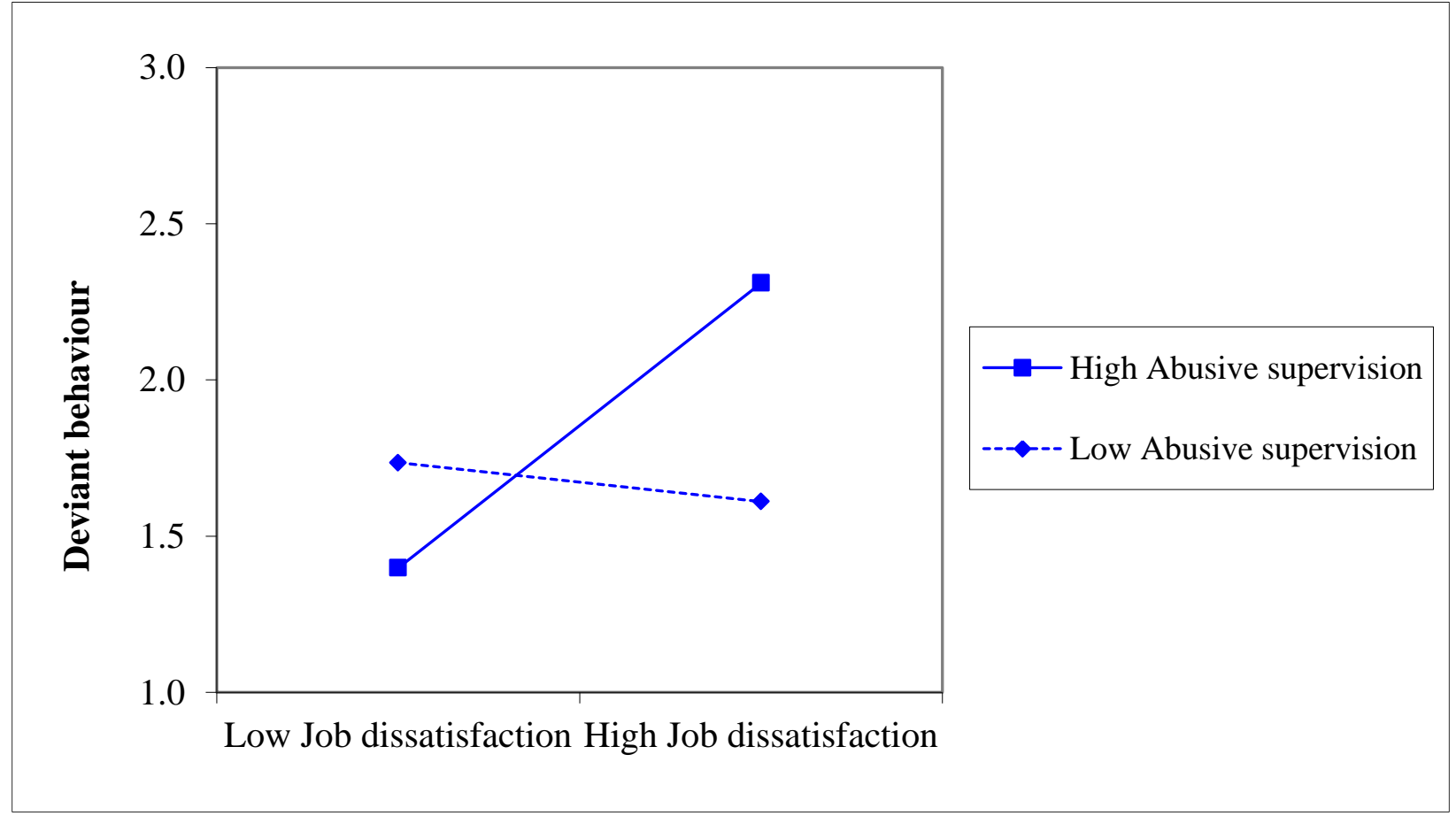

Figure 3: Moderating effect of adaptive humour on the relationship between job dissatisfaction and deviant behaviour

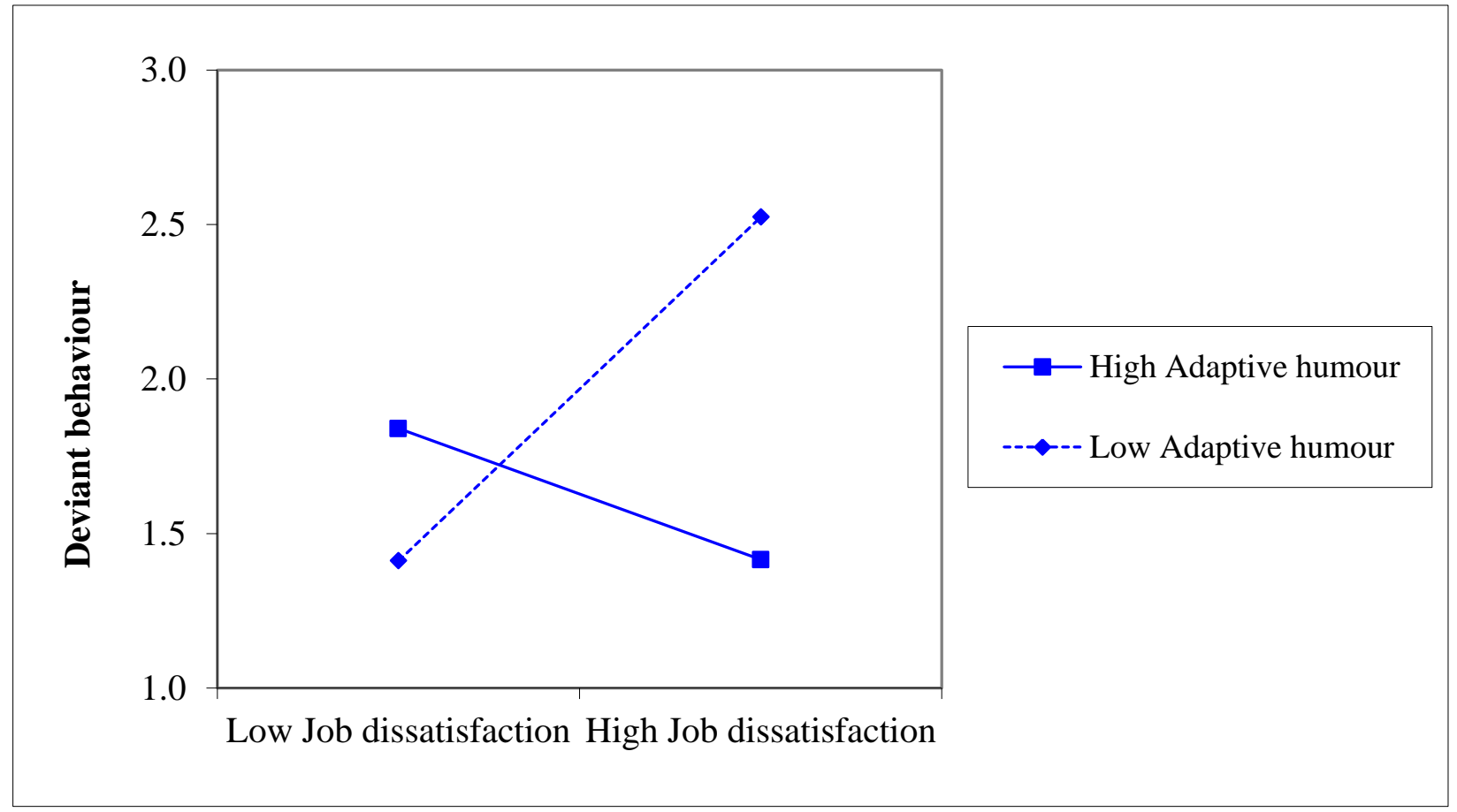


Figure 4: Three-way interaction effect

A: Adaptive humour on job dissatisfaction-deviant behaviour, high abusive supervision

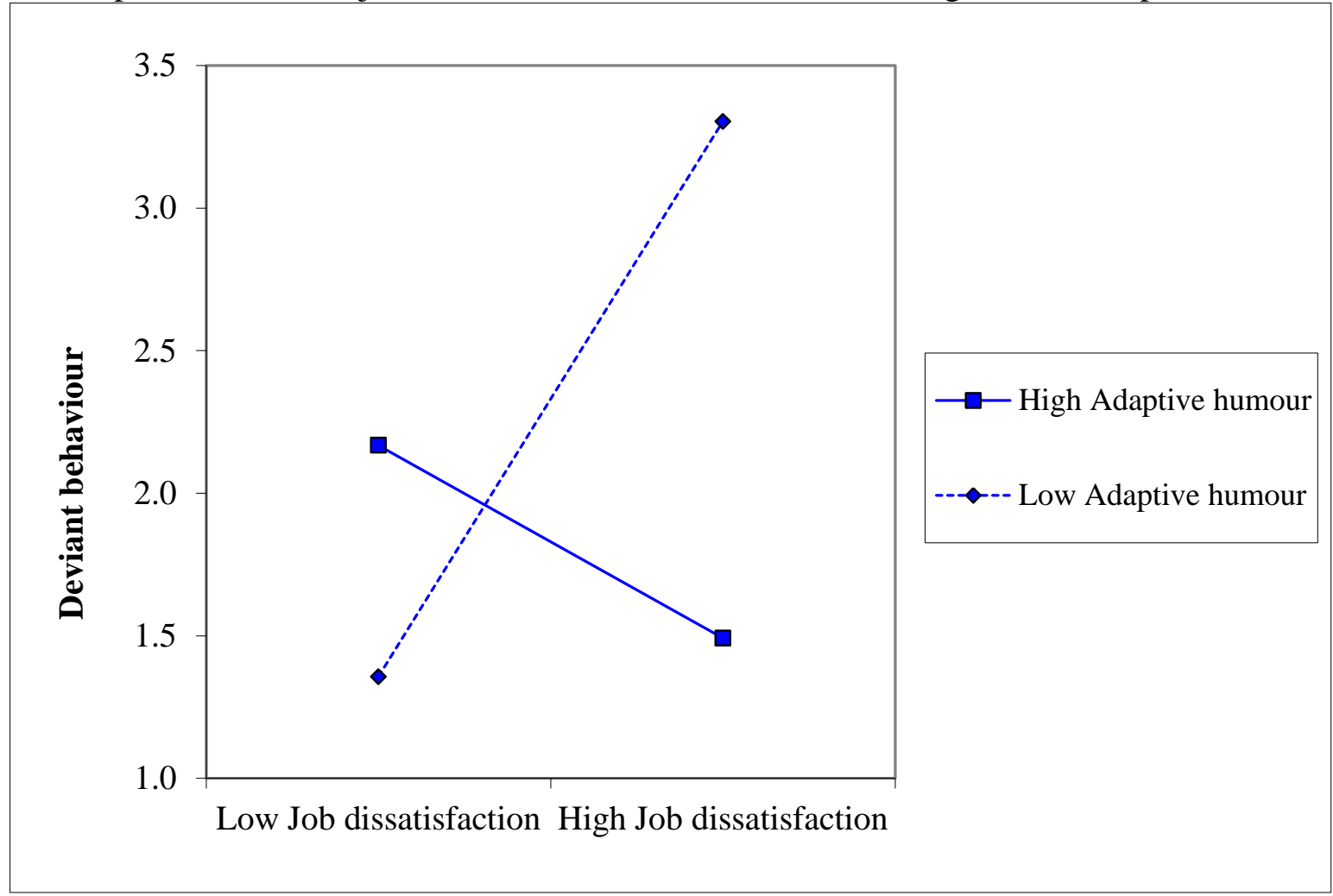

B: Adaptive humour on job dissatisfaction-deviant behaviour, low abusive supervision

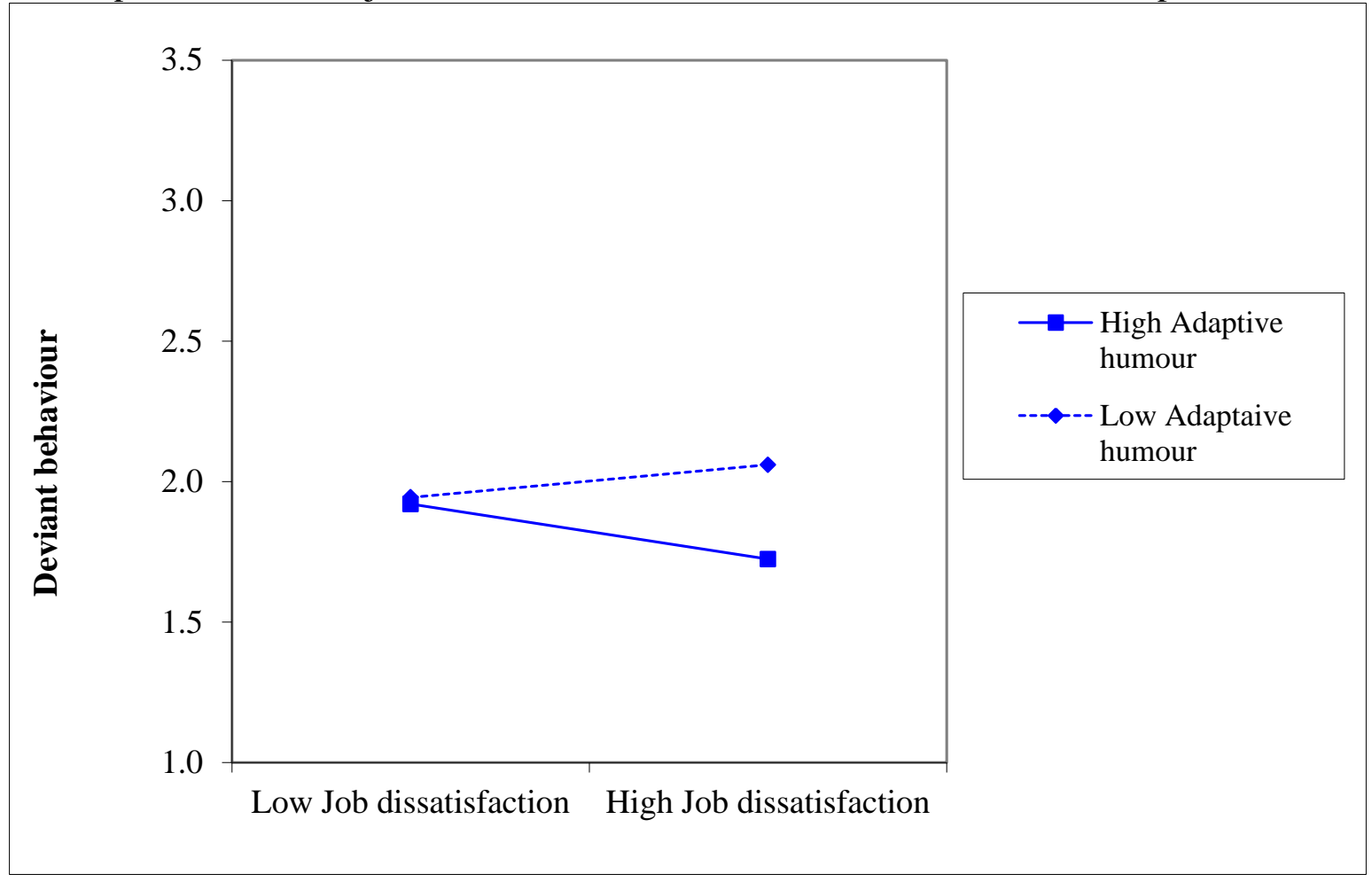


Table 1: Responses and demographic characteristics by organization

\begin{tabular}{|c|c|c|c|c|c|}
\hline & Organization 1 & Organization 2 & Organization 3 & Organization 4 & Organization 5 \\
\hline Industry & Manufacturing & Education & Media & Telecommunication & Banking \\
\hline Targeted employees & 100 & 60 & 125 & 50 & 25 \\
\hline Number of respondents & 70 & 34 & 86 & 21 & 10 \\
\hline Response rate & $70 \%$ & $57 \%$ & $69 \%$ & $42 \%$ & $40 \%$ \\
\hline \multicolumn{6}{|l|}{ Participant characteristics } \\
\hline Gender distribution ( $\%$ female) & $19 \%$ & $50 \%$ & $23 \%$ & $24 \%$ & $30 \%$ \\
\hline Age (6-point scale) & 2.64 & 2.35 & 2.31 & 2.57 & 2.40 \\
\hline Master's degree (\%) & $34 \%$ & $88 \%$ & $66 \%$ & $57 \%$ & $30 \%$ \\
\hline Organizational tenure (5-point scale) & 2.09 & 1.53 & 1.59 & 2.38 & 1.90 \\
\hline
\end{tabular}


Table 2: Correlation table and descriptive statistics

\begin{tabular}{|c|c|c|c|c|c|c|c|c|}
\hline \multirow{2}{*}{\multicolumn{9}{|c|}{ 1. Deviant behaviour }} \\
\hline & & & & & & & & \\
\hline 2. Job dissatisfaction & $.280 * *$ & & & & & & & \\
\hline 3. Abusive supervision & .113 & -.026 & & & & & & \\
\hline 4. Adaptive humour & $-.278 * *$ & .046 & $-.262 * *$ & & & & & \\
\hline 5. Gender $(1=$ female $)$ & -.069 & -.078 & $-.179 * *$ & $.213 * *$ & & & & \\
\hline 6. Age & $.155^{*}$ & -.009 & .024 & $-.225^{* *}$ & $-.159 *$ & & & \\
\hline 7. Education ( 1 = master's $)$ & -.114 & -.055 & -.049 & .041 & $.165^{*}$ & -.126 & & \\
\hline 8. Organizational tenure & $.156^{*}$ & .001 & -.028 & -.119 & $-.193 * *$ & $.676^{* *}$ & $-.201 * *$ & \\
\hline Mean & 1.462 & 2.465 & 1.929 & 2.895 & .262 & 2.452 & .570 & 1.828 \\
\hline Standard deviation & .498 & .498 & .753 & .720 & .441 & .728 & .496 & 1.017 \\
\hline
\end{tabular}

Notes: $\mathrm{N}=221$.

$* * p<.01 ; * p<.05$. 
Table 3: Regression results (dependent variable: deviant behaviour)

\begin{tabular}{|c|c|c|c|c|c|}
\hline & Model 1 & Model 2 & Model 3 & Model 4 & Model 5 \\
\hline Gender $(1=$ female $)$ & $\begin{array}{l}-.011 \\
(.076)\end{array}$ & $\begin{array}{c}.068 \\
(.073)\end{array}$ & $\begin{array}{c}.079 \\
(.072)\end{array}$ & $\begin{array}{c}.055 \\
(.069)\end{array}$ & $\begin{array}{c}.054 \\
(.068)\end{array}$ \\
\hline Age & $\begin{array}{c}.059 \\
(.059)\end{array}$ & $\begin{array}{c}.012 \\
(.057)\end{array}$ & $\begin{array}{c}.003 \\
(.056)\end{array}$ & $\begin{array}{c}.006 \\
(.054)\end{array}$ & $\begin{array}{l}-.005 \\
(.053)\end{array}$ \\
\hline Education $(1=$ master's $)$ & $\begin{array}{l}-.003 \\
(.070)\end{array}$ & $\begin{array}{l}-.022 \\
(.066)\end{array}$ & $\begin{array}{l}-.027 \\
(.065)\end{array}$ & $\begin{array}{l}-.030 \\
(.063)\end{array}$ & $\begin{array}{l}-.017 \\
(.062)\end{array}$ \\
\hline Organizational tenure & $\begin{array}{l}-.001 \\
(.044)\end{array}$ & $\begin{array}{c}.021 \\
(.041)\end{array}$ & $\begin{array}{c}.022 \\
(.041)\end{array}$ & $\begin{array}{c}.020 \\
(.039)\end{array}$ & $\begin{array}{l}.021 \\
(.039)\end{array}$ \\
\hline Organization 1 (manufacturing) & $\begin{array}{l}.252^{+} \\
(.135)\end{array}$ & $\begin{array}{l}.212 \\
(.130)\end{array}$ & $\begin{array}{l}.170 \\
(.129)\end{array}$ & $\begin{array}{l}.143 \\
(.124)\end{array}$ & $\begin{array}{l}.100 \\
(.124)\end{array}$ \\
\hline Organization 2 (education) & $\begin{array}{l}-.077 \\
(.152)\end{array}$ & $\begin{array}{l}.028 \\
(.144)\end{array}$ & $\begin{array}{l}-.024 \\
(.143)\end{array}$ & $\begin{array}{l}-.022 \\
(.138)\end{array}$ & $\begin{array}{l}-.060 \\
(.137)\end{array}$ \\
\hline Organization 3 (media) & $\begin{array}{l}-.099 \\
(.138)\end{array}$ & $\begin{array}{l}-.080 \\
(.129)\end{array}$ & $\begin{array}{l}-.134 \\
(.129)\end{array}$ & $\begin{array}{l}-.114 \\
(.123)\end{array}$ & $\begin{array}{l}-.162 \\
(.125)\end{array}$ \\
\hline Organization 4 (telecommunication) & $\begin{array}{l}.331 * \\
(.164)\end{array}$ & $\begin{array}{l}.350 * \\
(.157)\end{array}$ & $\begin{array}{l}.300^{+} \\
(.155)\end{array}$ & $\begin{array}{l}.353^{+} \\
(.149)\end{array}$ & $\begin{array}{l}.331^{*} \\
(.148)\end{array}$ \\
\hline $\mathrm{H}_{1}$ : Job dissatisfaction & & $\begin{array}{l}.197 * * \\
(.066)\end{array}$ & $\begin{array}{l}.197 * * \\
(.065)\end{array}$ & $\begin{array}{l}.172 * * \\
(.063)\end{array}$ & $\begin{array}{l}.149 * \\
(.063)\end{array}$ \\
\hline Abusive supervision & & $\begin{array}{l}.071^{+} \\
(.042)\end{array}$ & $\begin{array}{l}.091 * \\
(.042)\end{array}$ & $\begin{array}{l}.071^{+} \\
(.040)\end{array}$ & $\begin{array}{l}.084 * \\
(.040)\end{array}$ \\
\hline Adaptive humour & & $\begin{array}{c}-.186 * * * * \\
(.044)\end{array}$ & $\begin{array}{c}-.182 * * * \\
(.044)\end{array}$ & $\begin{array}{c}-.170 * * * \\
(.042)\end{array}$ & $\begin{array}{c}-.170 * * * \\
(.042)\end{array}$ \\
\hline $\mathrm{H}_{2}$ : Job dissatisfaction $\times$ abusive supervision & & & $\begin{array}{l}.259 * * \\
(.093)\end{array}$ & & $\begin{array}{l}.169^{+} \\
(.091)\end{array}$ \\
\hline $\mathrm{H}_{3}$ : Job dissatisfaction $\times$ adaptive humour & & & & $\begin{array}{c}-.384 * * * \\
(.080)\end{array}$ & $\begin{array}{c}-.367 * * * \\
(.081)\end{array}$ \\
\hline Adaptive humour $\times$ abusive supervision & & & & & $\begin{array}{l}-.080 \\
(.059)\end{array}$ \\
\hline $\begin{array}{l}\mathrm{H}_{4} \text { : Job dissatisfaction } \times \text { adaptive humour } \times \\
\text { abusive supervision }\end{array}$ & & & & & $\begin{array}{l}-.289 * \\
(.137)\end{array}$ \\
\hline $\begin{array}{r}\mathrm{R}^{2} \\
\mathrm{R}^{2} \text { change }\end{array}$ & .147 & .260 (113*** & $\begin{array}{l}.286 \\
.026^{* *}\end{array}$ & $\begin{array}{c}.333 \\
.073 * * *\end{array}$ & .366 \\
\hline
\end{tabular}

Notes: $\mathrm{N}=221$. The base case for the organization category is organization 5 (banking).

$* * * p<.001 ; * * p<.01 ; * p<.05 ;{ }^{+} p<.10$ (two-tailed tests); standard errors are in parentheses. 